\title{
Extraction and Enrichment of Lanthanide from Indonesian Low Grade Bauxite using Sulfuric Acid Heap Leaching and Phytic Acid
}

\author{
Eny Kusrini ${ }^{1, a}$, Agustino Zulys ${ }^{2, b}$, Azhar Yogaswara ${ }^{2}$, Wuwuh Wijang Prihandini' ${ }^{1}$, \\ Dwi Aprillia Wulandari'2, and Anwar Usman ${ }^{3}$
}

1 Department of Chemical Engineering, Faculty of Engineering, Universitas Indonesia, Kampus Baru UI Depok 16424, Indonesia

2 Department of Chemistry, Faculty of Mathematics and Sciences, Universitas Indonesia, Kampus Baru UI Depok 16424, Indonesia

3 Department of Chemistry, Faculty of Science, Universiti Brunei Darussalam, Jalan Tungku Link, Gadong BE1410 Negara Brunei Darussalam

Email : aekusrini@che.ui.ac.id (Corresponding author), bzulys@ui.ac.id (Corresponding author)

\begin{abstract}
The Indonesian low grade bauxite from Wacopek, Bintan Island is of high economic value because it has $0.0052 \%$ lanthanum oxide $\left(\mathrm{La}_{2} \mathrm{O}_{3}\right)$ and $0.0052 \%$ yttrium oxide $\left(\mathrm{Y}_{2} \mathrm{O}_{3}\right)$. In this study, the lanthanides ( $\mathrm{La}$ and $\mathrm{Y}$ ) have been successfully extracted from the low grade bauxite using heap leaching method with sulfuric acid, precipitated with trisodium phosphate and complexing with phytic acid (PA). The optimal concentration of $0.1 \mathrm{M}$ sulfuric acid $500 \mathrm{~mL}, 20 \mathrm{~g}$ bauxite could dissolve $24.39 \%$ lanthanum and $34.03 \%$ yttrium. After the extraction process using $\mathrm{H}_{2} \mathrm{SO}_{4}$, the extraction was followed by the precipitation reaction using trisodium phosphate (TSP). Phytic acid ligand has proven to precipitate some impurities such as $\mathrm{Al}, \mathrm{Fe}$ and $\mathrm{Mg}$ ions. Here, $\mathrm{PA}$ has successfully removed $57.125 \%$ of $\mathrm{Fe}^{3+}$ impurities in pregnant leach solution (PLS). After two times precipitation and complexing methods using TSP and PA, concentration of lanthanum and yttrium increased to $83.6 \%(0.04411 \mathrm{ppm})$ and $89.20 \%(0.28431 \mathrm{ppm})$, respectively. The phosphate groups of PA as active sites is favorable selective to bind with heavy metal ions. Based on these results, PA is used to precipitate the impurities and formed complexes, thus PA was expected to have high effectiveness for lanthanide enrichment. Finally, this complexing process with PA have succeeded enrichment of lanthanum to $83.6 \%$ (0.04411 ppm) and yttrium up to $89.20 \%(0.28431 \mathrm{ppm})$.
\end{abstract}

Keywords : Heap leaching, Indonesian low grade bauxite, lanthanide, phytic acid, sulfuric acid.

ENGINEERING JOURNAL Volume 24 Issue 4

Received 5 December 2019

Accepted 21 April 2020

Published 31 July 2020

Online at https://engj.org/

DOI:10.4186/ej.2020.24.4.305 


\section{Introduction}

Bauxite is the major ore for aluminum production. Alumina is extracted from bauxite by the Bayer process. The waste slurry generated in this process is called red mud and its solid fraction is called bauxite residue [1]. The $\mathrm{pH}$ of the wet red mud slurry is about 12 [2] and this is very dangerous for the ecosystem. Bauxite residue is stored in huge tailing ponds, and this could be a significant problem, since it not only occupies vast land areas, but it can also lead to environmental pollution [3] of the surrounding soil, air, and groundwater.

Annually, about 140 million tons of bauxite residue are produced [4], while more than $2.7 \times 10^{9}$ tons [5] were already stockpiled by 2011 . The cumulative amount of bauxite residue generated by 2015 is estimated to be close to $4 \times 10^{9}$ tons [6]. However, currently there are not many large volume applications of bauxite residue besides minor use in cement and ceramic production [1]. Nonetheless, bauxite residue contains several interesting minor or trace elements, among which the rare-earth elements (REEs) [79]. More than $90 \%$ of the trace metal value in bauxite residue can be attributed to the presence of REEs, one of them is yttrium [10].

The Indonesian low grade bauxite tailing from Wacopek (Bintan Island) contain $0.0052 \%$ of lanthanum oxide $\left(\mathrm{La}_{2} \mathrm{O}_{3}\right)$ and $0.041 \%$ of yttrium oxide $\left(\mathrm{Y}_{2} \mathrm{O}_{3}\right)$ [7-9]. These data provides very prospective information to obtain large added value through extraction of precious metals from low grade bauxite. Yttrium and lanthanum are widely used in astronomy, energy efficient lamps, ubiquitous electronic devices, other advanced materials used in defense, aerospace, energy infrastructure, household batteries, permanent maghnets, medical applications, luminescence, laser for surgical, ceramics, nuclear energy, steel industries, and the metallurgical industry [11-13]. Furthermore, yttrium radiopharmaceuticals have potential applications in the therapy of various cancers [14]. On the other hand, yttrium used as 5-HMF catalyst precursor, where the usefulness of 5Hydroxymethyl-furfural (5-HMF) can be an alternative development of petroleoum based energy resources and chemicals.

The presence of bauxite in nature is usually associated with other metal elements such as iron, silica, titanium and other impurities, rare earth and other metals [15]. So far there has no yet discovery of yttrium from Indonesian low grade bauxite, Bintan Island. Thus, the separation of lanthanum and yttrium from low grade bauxite is one of the innovation in the utilization of this source. On the other hand, it is also increasing the economical value of this waste. Therefore, efforts to extract it through enrichment methods, the most appropriate and efficient separation, is proposed in this study.

However, the separation and purification of lanthanum and yttrium from other elements is known to be difficult due to similar chemical and physical properties. To separate lanthanum and yttrium ions from REEs ore, one can use the heap leaching method. Heap leaching is one of the oldest and the most traditional mining process used to extract metal ions using chemical reagents, so the metal ions are released from the mineral [16]. The output of the heap leaching process is the dissolution of the desired metals, ionized with the added chemical solution. The advantages in using this method are cheaper, practical, simple design and equipment, lower energy, and does not need destruction $[17,18]$. According to Intelligence Mine's database, there are 283 heap leaching operation in processing precious metal, 123 heap leaching operation in base metals, and 24 heap leaching operation in other minerals such as REEs on worldwide. Heap leaching process is shown in Fig. 1, where the low grade bauxite was placed in buret, then acid solution which is sulfuric acid was infused to solid low grade bauxite using infusion cable that equipped wit flow adjust. The nature of the liquid that is likely for the lowest place, then the metal solution is collected in a liquid or commonly called Pregnant Leach Solution (PLS).

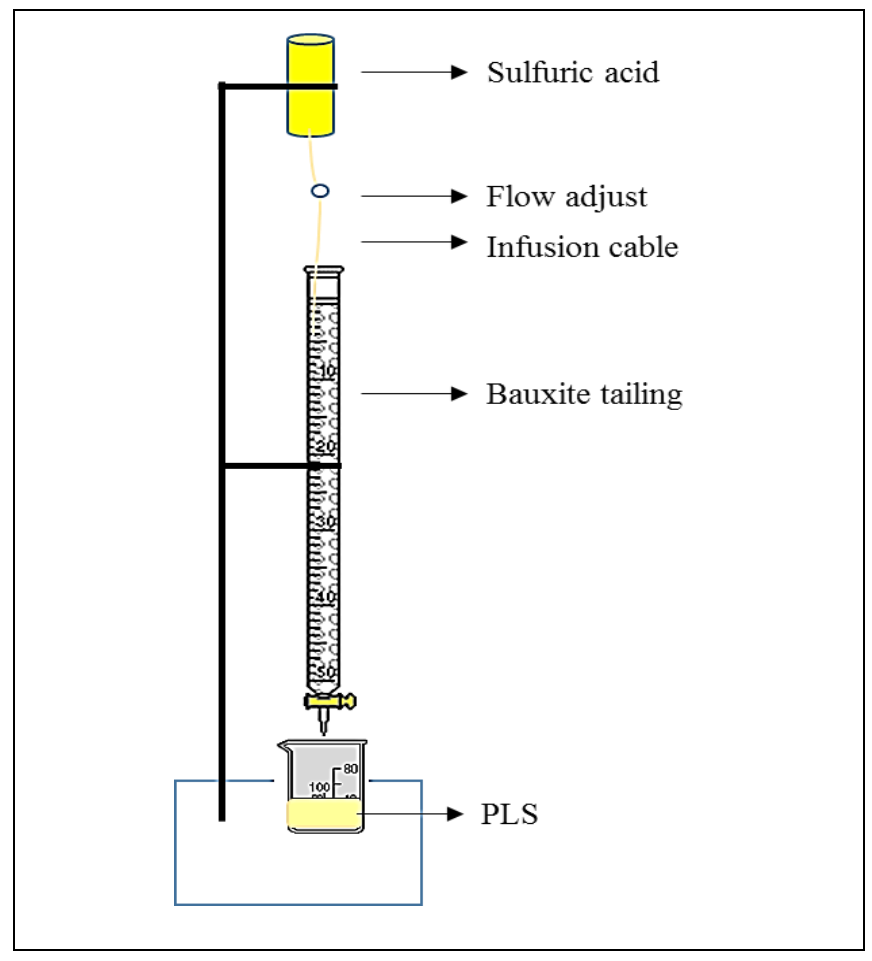

Fig. 1. Heap leaching process.

Ochsenkiihn-Petropulu et al. [19] investigated the recovery of lanthanides and yttrium from red mud by selective leaching diluted with nitric acid. The achieved recovery percentages were $90 \%(\mathrm{Y})$, heavy lanthanides (Dy, $\mathrm{Er}, \mathrm{Yb})$ up to $70 \%$, for the middle ones $(\mathrm{Nd}, \mathrm{Sm}, \mathrm{Eu}, \mathrm{Gd})$ up to $50 \%$ and for the group of lighter lanthanides (La, Ce, Pr) up to $30 \%$. Kusrini et al. [18] investigated the use of sulfuric acid heap leaching, precipitation and complexation with phytic acid to extract of lanthanum from Belitung silica sand particles.

After the precipitation process using trisodium phosphate, PLS is redissolved with acid and was added to phytic acid (PA) solution. Extraction using PA based on the principle of chelate formation, to form a complex with 
PA as ligand for separation of REEs becomes more selective. Phytic acid (PA) is well-known as a chelating agent for polyvalent metal ions which produced complexes with low solubility and resistance to heating, thus facilitating the separation process of lanthanides [18]. It is easily decomposed at neutral-pH either spontaneously or by microbial process to realese phospate anions and the cyclic sugar inositol as byproducts [19]. The hexaphosphate functional groups in PA allow it to combine with positively charged compounds (such as $\mathrm{Fe}^{2+}$, $\mathrm{Zn}^{2+}, \mathrm{Mg}^{2+}$ and $\mathrm{Ca}^{2+}$ ) and metal ions to form complex [20, 21].

In this study, extraction of lanthanum and yttrium ions from Indonesian low grade bauxite using heap leaching method with sulfuric acid as solvent and complexation with phytic acid (PA) were investigated in details. The phosphate groups of PA as active sites is favorable selective to bind with heavy metal ions $[18,23-$ 25 ]. This ligand is low toxicity, rich phosphate groups and strong complexing ability with metal ions [24]. Lanthanides have high affinity, thus they can form complexes between lanthanide ions and phosphate groups of phytic acid $[18,23]$. PA also can be used to precipitate some impurities [18]. It is supposed to have high effectiveness for lanthanide enrichment by complexing with PA as ligand.

\section{Experimental}

\subsection{Materials}

Low grade bauxite residue (bauxite tailing) was obtained from Wacopek, Bintan Island, Indonesia [7-9, 26]. The reagent such as sulfuric acid $\left(\mathrm{H}_{2} \mathrm{SO}_{4}\right)(97 \%$ Analytical Reagent Grade), distilled water, and ammonium hydroxide $\left(\mathrm{NH}_{4} \mathrm{OH}\right)$ (Analytical Reagent Grade) were purchased from Merck (Germany). Phytic acid (PA) solution $\left(50 \% \mathrm{w} / \mathrm{w} \mathrm{H}_{2} \mathrm{O}\right)$ and trisodium phosphate (TSP) (96\% Analytical Grade) were purchased from Sigma Aldrich (USA).

\subsection{Pre-Treatment of Indonesian Low Grade Bauxite}

The steps of pre-treatment low grade bauxite were cleaned, dried, and grinded of the sample using a ball-mill. The drying process was done using an oven at a temperature of $110^{\circ} \mathrm{C}$ for 2 hours $[8,26]$. The dried low grade bauxite was grinded and sieved to obtain the size of $2-5 \mathrm{~mm}$, thus the surface area is higher then it can make the acceleration of the solubility process during the heap leaching process become faster. Concentration of lanthanides in Indonesian low grade bauxite before acid leaching treatment is shown in Table 1. Based on the XRF analysis, the major composition in this sample are $\mathrm{Al}$ with concentration of $23.34 \%$, Si of $11.26 \%$ and $\mathrm{Fe}$ of $6.82 \%$.
Tabel 1. XRF analysis of fresh Indonesian low grade bauxite before treatment.

\begin{tabular}{cc}
\hline Element & Concentration $(\%)$ \\
\hline $\mathrm{Al}$ & 23.34 \\
$\mathrm{Si}$ & 11.26 \\
$\mathrm{Fe}$ & 6.82 \\
$\mathrm{Ti}$ & 0.547 \\
$\mathrm{Mn}$ & 0.0074 \\
$\mathrm{Na}$ & 0.0084 \\
$\mathrm{Ca}$ & 0.0033 \\
$\mathrm{Mg}$ & 0.0295 \\
$\mathrm{Zn}$ & 0.044 \\
$\mathrm{Cr}$ & 0.0023 \\
$\mathrm{Rb}$ & 0.0029 \\
$\mathrm{Zr}$ & 0.0429 \\
$\mathrm{~V}$ & 0.0077 \\
$\mathrm{Th}$ & 0.01 \\
$\mathrm{Y}$ & 0.0041 \\
$\mathrm{Nb}$ & 0.0036 \\
$\mathrm{La}$ & 0.0035 \\
$\mathrm{Ga}$ & 0.0073 \\
$\mathrm{~K}$ & 0.713 \\
\hline
\end{tabular}

\subsubsection{Heap leaching using sulfuric acid}

The concentration of sulfuric acid $(500 \mathrm{~mL})$ used in this study was varied with concentration of $0.01 \mathrm{M} ; 0.1 \mathrm{M}$; $0.5 \mathrm{M} ; 1 \mathrm{M}$; and $2.5 \mathrm{M}$. This acid solution was made from dilution of concentrated sulfuric acid with distilled water. The sulfuric acid was put in the reactor and then it was dropped to Indonesian low grade bauxite (20 $\mathrm{g}$ weight and 2-5 $\mathrm{mm}$ in size). After that, each $50 \mathrm{~mL}$ of Pregnant Leach Solution (PLS) was kept in a container bottle. Each the result of heap leaching process in variation acid concentration $0.01 \mathrm{M} ; 0.1 \mathrm{M} ; 0.5 \mathrm{M} ; 1 \mathrm{M}$ and $2.5 \mathrm{M}$ were named in sequences of PLS 0.01, PLS 0.1, PLS 0.5, PLS 1 and PLS 2.5. The lanthanide ( $\mathrm{La}$ and $\mathrm{Y}$ ) ions concentrations from each PLS samples were determined using ICP-OES.

2.2.2. Precipitation reaction of lanthanide ions from PLS using trisodium phospate (TSP)

$\mathrm{pH}$ of PLS was adjusted to $\mathrm{pH}$ using $\mathrm{NH}_{4} \mathrm{OH}$ and under stirring. Solution was added TSP according to stoichiometric comparison which has been done under stirring at $80^{\circ} \mathrm{C}$ for 60 minutes. After that, the precipitate was filtered. After the precipitate was completely filtered, the filtrate was dried. This first precipitate (FP) was used for further complexing with phytic acid as ligand.

\subsubsection{Job method for precipitating ion $\mathrm{Fe}^{3+}$ using $\mathrm{PA}$ ligand}

$\mathrm{Fe}^{3+}$ solution was made from the mixture of $4 \mathrm{mM}$ pregnant liquid solution (PLS) and $1.1 \mathrm{mM}$ phytic acid (PA) solution. Both solution was mixed with distilled water and $1 \mathrm{M}$ sulfuric acid into a centrifuge tube with the volume 
according to Table 2 . The mixed solution was shaken and allowed to stand for 5 minutes. The mixture was centrifuged for 15 minutes and filtered using a filter paper. Measurement of concentration of $\mathrm{Fe}^{3+}$ ion was determined using a UV-Vis spectrophotometer.

Table 2. Variation concentration of Job method between $\mathrm{Fe}^{3+}$ and $\mathrm{PA}$.

\begin{tabular}{ccccccccc}
$\begin{array}{c}\mathrm{mMol} \\
\mathrm{Fe}^{3+}\end{array}$ & $\begin{array}{c}\mathrm{mMol} \\
\mathrm{PA}\end{array}$ & $\begin{array}{c}\mathrm{V} \\
\mathrm{Fe}^{3+} \\
(\mathrm{mL})\end{array}$ & $\begin{array}{c}\mathrm{V} \\
\mathrm{PA} \\
(\mathrm{mL})\end{array}$ & $\begin{array}{c}\mathrm{V} \\
\mathrm{PA} \\
(\mathrm{mL})\end{array}$ & $\begin{array}{c}\mathrm{V} \\
\text { distilled } \\
\text { water } \\
(\mathrm{mL})\end{array}$ & $\begin{array}{c}\mathrm{VTotal} \\
(\mathrm{mL})\end{array}$ & $\begin{array}{c}\mathrm{M} \\
\mathrm{PA}\end{array}$ & $\begin{array}{c}\mathrm{M} \\
\mathrm{Fe}\end{array}$ \\
\hline 3 & 7 & 0.8 & 4.62 & 5 & 14.57 & 25 & 0.28 & 1.68 \\
4 & 6 & 1.1 & 3.96 & 5 & 14.96 & 25 & 0.24 & 1.44 \\
5 & 5 & 1.4 & 3.30 & 5 & 15.35 & 25 & 0.2 & 1.2 \\
6 & 4 & 1.6 & 2.64 & 5 & 15.74 & 25 & 0.16 & 0.96 \\
7 & 3 & 1.9 & 1.98 & 5 & 16.13 & 25 & 0.12 & 0.72 \\
8 & 2 & 2.2 & 1.32 & 5 & 16.52 & 25 & 0.08 & 0.48 \\
9 & 1 & 2.4 & 0.66 & 5 & 16.91 & 25 & 0.04 & 0.24 \\
\hline
\end{tabular}

2.2.4. Precipitation and complexing reaction of lanthanide ions from PLS using phytic acid

First precipitate (FP) was dissolved in $0.1 \mathrm{M} \mathrm{H}_{2} \mathrm{SO}_{4}$. Then $10 \mathrm{~mL}$ of PLS solution was added phytic acid according to the amount of lanthanide stoichiometrically using a UV-Vis spectrophotometer.. After that, the measurements of lanthanide ions concentration were conducted using a Inductively Coupled Plasma-Optical Emission Spectrometry (ICP-OES).

\subsection{Characterization}

The functional groups of samples were recorded by FTIR spectroscopy in the region $4000-400 \mathrm{~cm}^{-1}$.

The initial concentrations of low grade bauxite such as alumium $(\mathrm{Al})$, silica $(\mathrm{Si})$, iron $(\mathrm{Fe})$, titanium $(\mathrm{Ti})$, mangan $(\mathrm{Mn})$, magnesium $(\mathrm{Mg})$, zirconium $(\mathrm{Zr})$, chloride $(\mathrm{Cl})$, vanadium $(\mathrm{V})$, thorium $(\mathrm{Th})$, yttrium $(\mathrm{Y})$, niboium $(\mathrm{Nb})$, lanthanum (La), galium $(\mathrm{Ga})$, potassium $(\mathrm{K})$ were determined by XRF.

The concentration of leached samples such as aluminum $(\mathrm{Al})$, iron $(\mathrm{Fe})$, magnesium $(\mathrm{Mg})$, lanthanum (La), and yttrium (Y) were determined by ICP_OES using an ICP 6000 series spectrometer (Thermo Scientific).

\section{Results and Discussion}

\subsection{Sulfuric Acid Heap Leaching}

Based on the XRF results, the content of $\mathrm{Y}$ and La from the Indonesian low grade bauxite was found of 0.0041 and $0.0035 \%$, respectively (see Table 1 ). Other component was considered as impurity metal which was dominated by three major componentsm namely $\mathrm{Al}, \mathrm{Si}$ and $\mathrm{Fe}[8,26]$. On the other hand, the yttrium content in
Indian red mud that reported by Abhilash and coworkes [27] is only $0.001 \%$. This amount is smaller compared with the concentration of the sample in this study by $0.0041 \%$. From this number, it can be concluded that the Indonesian low grade bauxite from Bintan Island has greater potential for lanthanum nad yttrium extraction compared to bauxite that reported by Abhilash and patners [27]. Schematic process for heap leaching, precipitation and complexing with PA is described in Fig. 2.

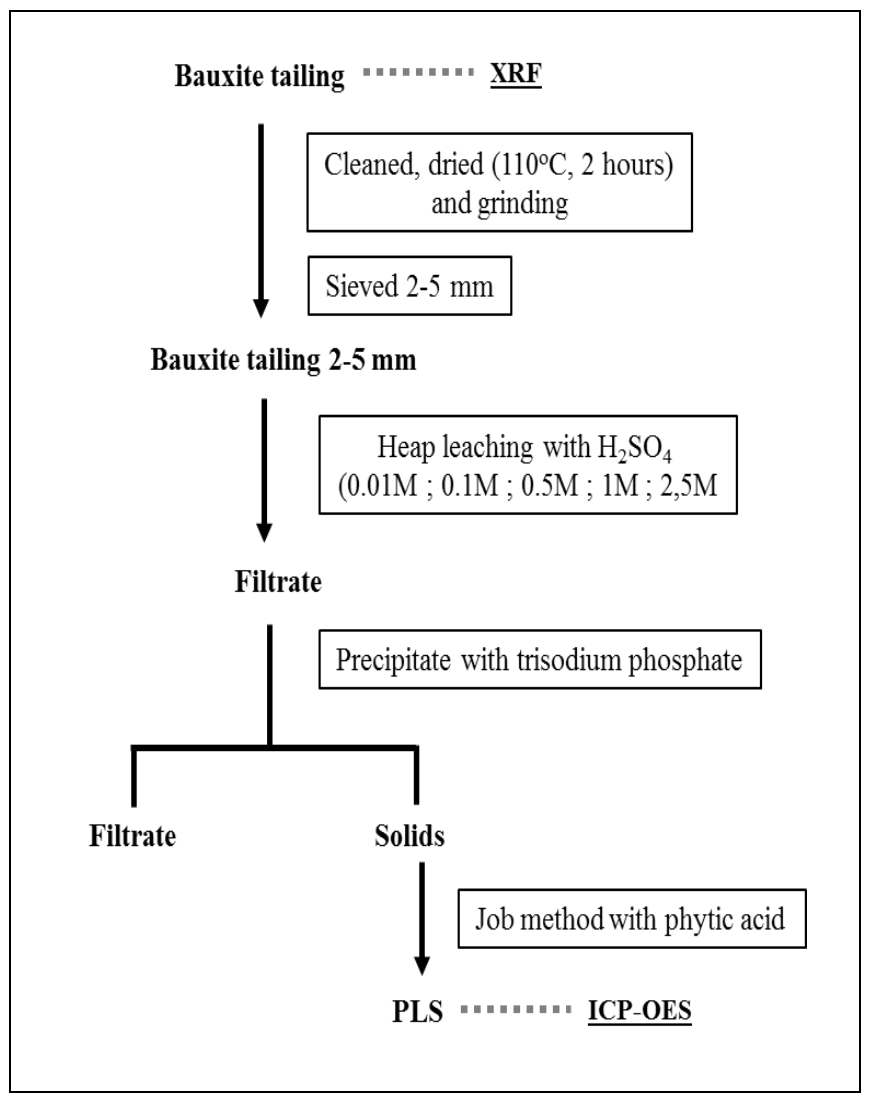

Fig. 2. Schematic process heap leaching using sulphuric acid, precipitation method using TSP and complexing reaction with PA ligand.

It is very important to select the optimal condition in acid leaching process in order to obtain the high amount of lanthanide and minimum of impurities. Meanwhile, the use of sulfuric acid in the REEs leaching process can obtain the optimal results if acid solutions that have high concentrations, however in low temperatures, thus it can cause the reducing and minimizing of impurities. The reaction occured between sulfuric acid and REEs is shown in Eq. (1) [7, 28].

$$
3 \mathrm{H}_{2} \mathrm{SO}_{4(\mathrm{aq})}+\mathrm{REE}_{2} \mathrm{O}_{3(\mathrm{~s})} \rightarrow \mathrm{REE}_{2}\left(\mathrm{SO}_{4}\right)_{3(\mathrm{aq})}+3 \mathrm{H}_{2} \mathrm{O}_{(\mathrm{l})}
$$

There are some factors that influence the results of REEs leaching using sulfuric acid, one of them is solubility of lanthanides. The solubillity it self will increase if the liquid and solid (L/S) ratio of the solution approaches $15 \mathrm{~mL} / \mathrm{g}$, while the increasing of acid solvent concentration also increases the solubility of REEs and 
also their impurities. From these results, the optimum concentration is needed to avoid the solubility of impurities. Table 3 shows the lanthanide contained in the PLS results from the heap leaching process using sulfuric acid with various concentrations. From the data it can be seen that optimum concentration sulfuric acid for extraction lanthanum is $0.1 \mathrm{M}$ which result $0.03411 \mathrm{ppm}$ of lanthanum, while for the highest yttrium content was found at concentrations of $0.1 \mathrm{M}$ and $2.5 \mathrm{M}$ which are $0.05568 \mathrm{ppm}$ and $0.05307 \mathrm{ppm}$, respectively. The difference of extraction results obtained between $\mathrm{Y}$ and $\mathrm{La}$ is because of the different ionic radii of $\mathrm{La}$ and $\mathrm{Y}$ itself. From these results, lanthanum $(\mathrm{La})$ has ionic radius of 250 $\mathrm{pm}$ has better solubility in sulfuric acid compared to yttrium (Y) with ionic radius of $240 \mathrm{pm}$. The similar finding has similar been observed and reported by Borra et al. [10] that the smaller radii increase the solubility and enhance the extraction results.

Table 3. Lanthanide content in PLS measured by ICPOES.

\begin{tabular}{ccc}
\hline \multirow{2}{*}{ Sample } & \multicolumn{2}{c}{ ICP OES Results } \\
\cline { 2 - 3 } & $\mathrm{La}(\mathrm{ppm})$ & $\mathrm{Y}(\mathrm{ppm})$ \\
\hline PLS 0.01 M & 0.01574 & 0.01442 \\
PLS 0.1 M & 0.03411 & 0.05568 \\
PLS 0.5 M & 0.00723 & 0.03069 \\
PLS 1M & 0.00434 & 0.02945 \\
PLS 2.5 M & 0.0002 & 0.05307 \\
\hline
\end{tabular}

As we noted that the percentage extraction of lanthanides is different because of the association of lanthanides with different ores and their ionic radii [10]. For example, some of the cerium in the bauxite residue is present in the form of $\mathrm{CeO}_{2}$ or bastnaesite $\left((\mathrm{Ce}, \mathrm{La}) \mathrm{CO}_{3} \mathrm{~F}\right)$ [29] and is difficult to leach, it is not completely soluble in the acid solutions, but the extraction is high for $\mathrm{Y}$, followed by Dy, Nd, Sc, La and Ce. This also depends on the type REEs and their ionic radii [10].

Percentage of lanthanide content in PLS from Heap leaching process in variation of sulfuric acid concentration from 0.01 to $2.5 \mathrm{M}$ is shown in Table 4. From that data, lanthanum content of $0.001 \%$ was obtained at $0.1 \mathrm{M}$ sulfuric acid and dissolving ability of lanthanum of $24.39 \%$. On the other hand, yttrium content at $0.1 \mathrm{M}$ and $2.5 \mathrm{M}$ sulfuric acid was $0.00177 \%$ and $0.001685 \%$ with the solubility ability percentage being $34.03 \%$ and $32.40 \%$, respectively.

Each PLS result from heap leaching in variation concentration of sulfuric acid is shown in Fig. 3.
Table 4. Concentration of PLS in heap leaching treatment using sulphuric acid with concentration from 0.01 to 2.5 M.

\begin{tabular}{ccccc}
\hline Sample & $\begin{array}{c}\mathrm{La}_{2} \mathrm{O}_{3} \\
(\mathrm{mg})\end{array}$ & $\begin{array}{c}\mathrm{Y}_{2} \mathrm{O}_{3} \\
(\mathrm{mg})\end{array}$ & $\mathrm{La}(\%)$ & $\mathrm{Y}(\%)$ \\
\hline PLS 0.01 M & 0.092 & 0.0916 & 0.00046 & 0.000458 \\
PLS 0.1 M & 0.200 & 0.3540 & 0.00100 & 0.00177 \\
PLS 0.5 M & 0.0042 & 0.1949 & 0.00021 & 0.000975 \\
PLS 1 M & 0.0025 & 0.1870 & 0.000125 & 0.000935 \\
PLS 2.5 M & 0.0012 & 0.3370 & 0.000006 & 0.001685 \\
\hline
\end{tabular}

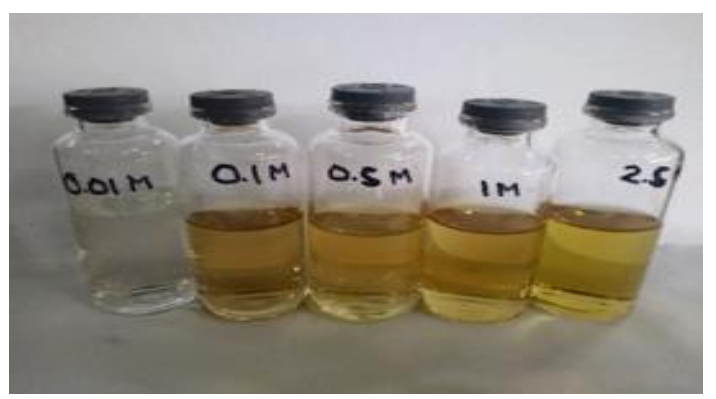

Fig. 3. PLS after heap leaching process using sulfuric acid.

\subsection{Precipitation Reaction of Lanthanide Ions from PLS Using TSP}

The PLS resulting from the sulfuric acid heap leaching still contains impurities which are also dissolved in sulfuric acid solution. To purify the PLS samples, the REEs was precipitated using trisodium phosphate (see Table 5). The precipitations of yttrium and lanthanides from low concentration sulfate solutions by the addition of sodium phosphate solution have also reported by Beltrami et al. [30], Agin et al. [31], and Donati et al. [32]. Due to the strong affinity of $\mathrm{Y}^{3+}(\mathrm{aq})$ and $\mathrm{Ln}^{3+}(\mathrm{aq})$ ions for $\mathrm{PO}_{4^{3}}{ }^{3}(\mathrm{aq})$ compared to $\mathrm{SO}_{4}{ }^{2}(\mathrm{aq})$, the addition of $\mathrm{Na}_{3} \mathrm{PO}_{4}(\mathrm{aq})$ to a sulfate solution of yttrium and lanthanides was expected to produce the precipitated of REE phosphate, as shown in Eq. (2), even at low concentration of REEs.

$$
\mathrm{REE}\left(\mathrm{SO}_{4}\right)^{3-2 \mathrm{n}_{\mathrm{n}}}+\mathrm{PO}_{4}{ }^{3-} \rightarrow \mathrm{REE}\left(\mathrm{PO}_{4}\right)+{ }_{\mathrm{n}} \mathrm{SO}_{4}{ }^{2-}
$$

In the REEs precipitated process, the $\mathrm{pH}$ is important because the PLS containing several protons that will reach equilibrium resulting in precipitation reaction. $\mathrm{pH}$ has an important role to avoid the precipitation of impurity metals [19]. The amount of TSP was added to the PLS at ratio $1: 1$ corresponds to the results its stoichiometry. If the addition of trisodium phosphate is not according with the calculation of stoichiometry may result in the unstable precipitated of REEs. 
Table 5. Comparison the concentration of lanthanides and their impurities in the precipitation reaction with and without TSP agent.

\begin{tabular}{|c|c|c|c|c|c|c|}
\hline \multirow{2}{*}{ Sample } & \multirow{2}{*}{ 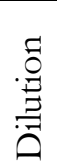 } & \multicolumn{5}{|c|}{$\begin{array}{l}\text { ICP OES Results } \\
(\mathrm{ppm})\end{array}$} \\
\hline & & $\mathrm{La}$ & $\mathrm{Y}$ & $\mathrm{Al}$ & $\mathrm{Mg}$ & $\mathrm{Fe}$ \\
\hline PLS pH & & & & & & \\
\hline $\begin{array}{l}3.5 \\
\text { withou } \\
\text { t TSP }\end{array}$ & 10 & $\begin{array}{c}0.0072 \\
3\end{array}$ & $\begin{array}{c}0.030 \\
69\end{array}$ & $\begin{array}{l}178 \\
6.1\end{array}$ & $\begin{array}{c}10.6 \\
87\end{array}$ & $\begin{array}{c}533.9 \\
63\end{array}$ \\
\hline $\begin{array}{c}\text { PLS pH } \\
3.5 \\
+ \text { TSP } \\
\end{array}$ & 10 & $\begin{array}{c}0.015 \\
13\end{array}$ & $\begin{array}{l}0.15 \\
972\end{array}$ & $\begin{array}{l}563 . \\
623\end{array}$ & $\begin{array}{l}7.27 \\
193\end{array}$ & $\begin{array}{l}24.6 \\
925\end{array}$ \\
\hline $\begin{array}{c}\text { Percenta } \\
\text { ge }(\%)\end{array}$ & & 47.78 & $\begin{array}{c}80.7 \\
8 \\
\end{array}$ & $\begin{array}{c}68.4 \\
4 \\
\end{array}$ & $\begin{array}{c}31.9 \\
5 \\
\end{array}$ & $\begin{array}{c}95.3 \\
7 \\
\end{array}$ \\
\hline
\end{tabular}

The reaction between the trisodium phosphate and the lanthanide sulfate is shown in Eq. (2). The sulfate ions in REEs sulfate was substituted and reacted with oxygen of the phosphate ions, then produced Ln phosphate compound. To increase the selectivity of precipitation reaction of $\mathrm{Ln}$ using TSP, $\mathrm{pH}$ was adjusted using $\mathrm{NH}_{4} \mathrm{OH}$ solution. This parameter was also considered in hydrometallurgical processes. Concerning to the system, several proton-equilibria take place. Indeed, the $\mathrm{Ln}^{3+}, \mathrm{Al}^{3+}$ and $\mathrm{Fe}^{3+}$ ions can be easily hydrolyzed and the phosphate ion, used to precipitate the Ln metal can be simply doubly or triply protonated. Therefore, the $\mathrm{pH}$ of precipitation was expected to play important role on the precipitation reaction of $\mathrm{REEPO}_{4}$ [33].

In the case of iron, Beltrami et al. [30] has reported and identified the precipitation yield started to increase at $\mathrm{pH} 3$ due to the precipitation of $\mathrm{Fe}(\mathrm{OH})_{3}, \mathrm{FePO}_{4}(\mathrm{~s})$ and $\mathrm{Fe}_{3}\left(\mathrm{PO}_{4}\right)_{2} \cdot \mathrm{xH}_{2} \mathrm{O}(\mathrm{s})$. Hence, precipitation at $\mathrm{pH} 4$ gives the best condition between the quantitative recovery of REE and iron contamination, thus the optimum $\mathrm{pH}$ for precipitation of REEs was adjusted at the $\mathrm{pH}$ of 3.5, if $\mathrm{pH}$ is greater than 4 , the possibility of precipitation of iron ions will be greater. This excess $\mathrm{pH}$ level should be avoided to minimize the impurities which is iron ions. TSP agent was added to precipitate REEs because TSP diffusion in PLS liquid surface, as a result the concentrations of REEs increased in PLS.

Decreasing the impurity concentration in the PLS after precipitation reaction with TSP and after adding TSP were added is summarized in Table 5. Decrease concentration of iron ions in PLS is about $95.37 \%$ from 533.963 to $24.6925 \mathrm{ppm}$. Lanthanum in PLS concentration was increased up to $47.78 \%$ from 0.00723 to $0.01513 \mathrm{ppm}$. At the concentration of yttrium in PLS after TSP was added increased up to $80.78 \%$ from 0.03069 to $0.15972 \mathrm{ppm}$. Thus, the addition of TSP can increase the extraction of REEs from Indonesian low grade bauxite and reduce the dissolution of impurities by adjusting the selective $\mathrm{pH}$ at 3.5 when adding TSP.

\subsection{Job method}

Before PA solution was added directly to phosphate precipitated, PA ligand must first be recognized for its effectiveness when used in a solution with an acidic atmosphere. In addition, $\mathrm{Fe}^{3+}$ is a quite dominant disturbing ion in the precipitated with TSP, this ion is greatly interfered with the extraction process of lanthanum and yttrium because it can reduce concentration of yttrium and lanthanum. Therefore, the presence of $\mathrm{Fe}^{3+}$ ions must be eliminated from the solution. PA ligand can react with $\mathrm{Fe}^{3+}$ ions and produce a white precipitated compound. However, the reaction must be stoichiometrically known using the job method in order to save the amount of PA used for compexation reaction. The precipitate produced in the reaction of $\mathrm{Fe}^{3+}$ with $\mathrm{PA}$ ligand in an acidic condition is smooth and very mild. This causes the measurement of the job method with gravimetry is difficult to conduct. Therefore, it is used measurements with a UV-Vis spectrophotometer at $300 \mathrm{~nm}$. Figure 4 showed the result of the Job method that results in the intersection of lines at $0.80 ; 0.00062$.

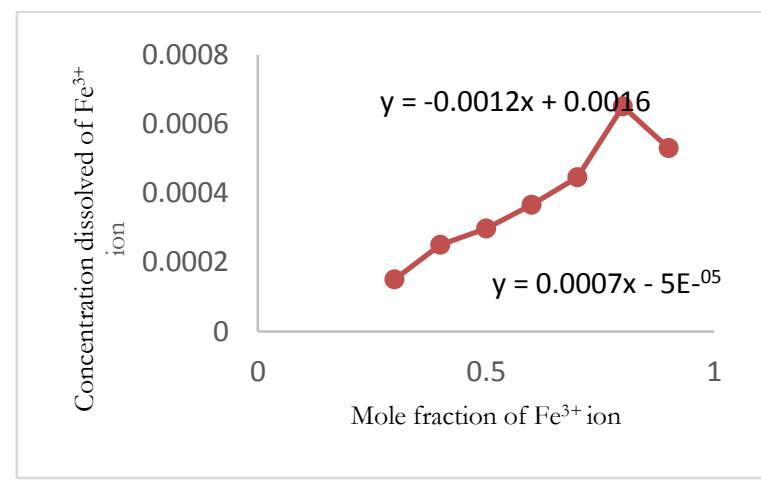

Fig. 4. Job method to determine the concentration of PA ligand.

The fraction of $\mathrm{Fe}^{3+}$ is 0.80 mole or the ratio of $\mathrm{Fe}^{3+}$ mole and PA ligand is $0.80 / 0.20$. This comparison is in accordance with the amount of acid that can produce phytic acid. Thus, it can be concluded that PA ligand can still be effectively used in acidic conditions without hydrolysis of the phosphate ester group. The reaction is predicted in below (see Eq. (3)).

$$
\begin{array}{r}
\mathrm{C}_{6} \mathrm{H}_{6}\left(\mathrm{OPO}_{3} \mathrm{H}_{2}\right)_{6}(\mathrm{aq})+4 \mathrm{Fe}\left(\mathrm{H}_{2} \mathrm{O}\right)_{6}{ }_{6}{ }^{3+}(\mathrm{aq}) \rightarrow \\
\mathrm{Fe}_{4}\left(\mathrm{C}_{6} \mathrm{H}_{6}\left(\mathrm{OPO}_{3}\right)_{6}(\mathrm{~s})+12 \mathrm{H}_{2} \mathrm{O}(\mathrm{l})+12 \mathrm{H}_{3} \mathrm{O}^{+}(\mathrm{aq})\right.
\end{array}
$$

\subsection{Precipitation of the PLS with Phytic Acid}

\subsubsection{Characterization using FTIR spectroscopy}

PLS was formed as brown precipitate compound after reacted with trisodium phosphate (TSP) agent. This precipitate was diluted again using sulfuric acid to be reprecipitated and complexed using PA as ligand. The addition of PA produced a white precipitate complex, which PA acted as a chelating agent [23-25]. To ensure the 
complex was formed, structure of the complex and its ligand was characterized using FTIR, as shown in Fig. 5. The presence of water molecules in the structures of the PA was confirmed by the broad absorption bands in the range of $3600-2800 \mathrm{~cm}^{-1}$ assigned to the streching vibration of $v(\mathrm{O}-\mathrm{H})$ groups from hydrogen bonded water molecules. No appearance of absorption at $1200 \mathrm{~cm}^{-1}$ is assigned to symmetric bending vibration $v(\mathrm{P}=\mathrm{O})$ and 926 $\mathrm{cm}^{-1}$ is assigned to the streaching $v(\mathrm{P}-\mathrm{OR})$. This indicated that the PA is bound to form a complex with the metals contained in PLS $[34,35]$.

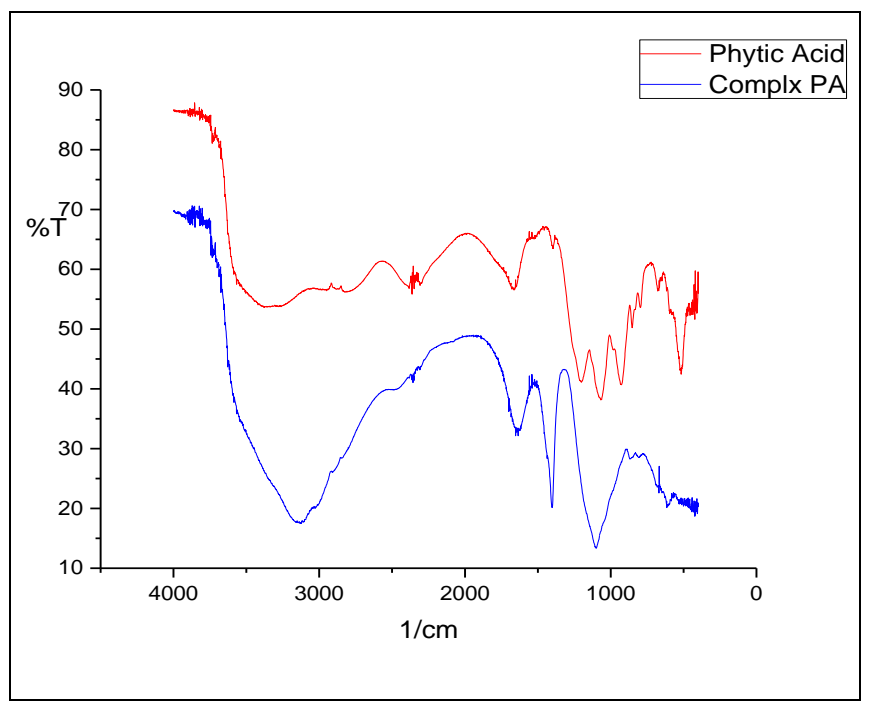

Fig. 5. Comparison FTIR spectra of phytic acid ligand and its complex.

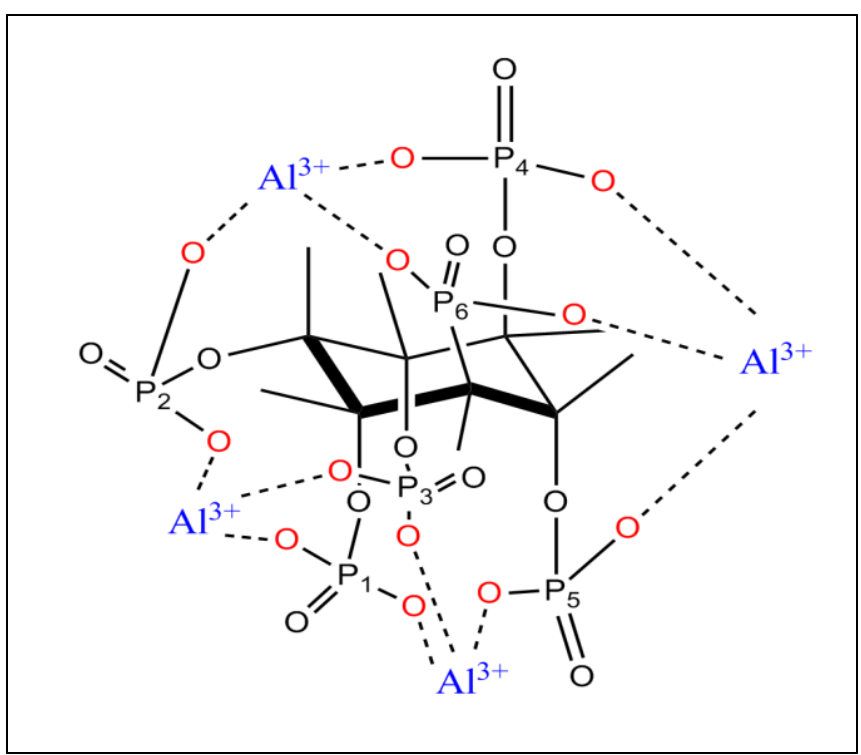

Fig. 6. Illustration of complexing between $\mathrm{Al}^{3+}$ ions and hexaphosphate groups of phytate anion.

Absorption at $1050 \mathrm{~cm}^{-1}$ was identified as trivalent phospate metal and based on the obtained concentration value and the equilibrium constant of $\mathrm{Al}^{3+}$ ions forming complex compounds with PA ligand [34]. PA ligand has deprotonated and produced phytate anion, thus it can coordinate with the metal ions to form complexes [18].
Here, the hexaphosphate groups of phytate anion has formed a complexing with the $\mathrm{Al}^{3+}$ ions via bidentate mode (see Fig. 6), thus concentration of $\mathrm{Al}$ is reduced.

The hexaphosphate groups of phytic anion can be used as active sites and it is favorable selective to bind with impurities metal such as $\mathrm{Al}^{3+}$ ions. Phytic acid ligand has proven to precipitate some impurities metals such as $\mathrm{Al}$, $\mathrm{Fe}$ and $\mathrm{Mg}$ ions. It it similar was observed with previous study for enrichment of lanthanum from Belitung silica sand [18]. This method is expected to have high effectiveness for lanthanum and yttrium enrichment from Indonesian low grade bauxite using the series treatment that reported in this study. On the other hand, phytic anion is also used as chelating agent so that it can form a complex with proteins and also is very selective to minerals such as $\mathrm{Eu}^{3+}$ [24], $\mathrm{Cu}^{2+}, \mathrm{Al}^{3+}$ and $\mathrm{V}^{4+}[36]$.

\subsubsection{Analysis of metals content in PLS after complexing using phytic acid ligand}

The concentration of $\mathrm{Fe}^{3+}$ in the precipitate is 14.1056 ppm. This precipitation process can be removed $\mathrm{Fe}^{3+}$ concentration by $57.125 \%$. The solubility of $\mathrm{Mg}^{2+}$ ions is greater than the solubility of $\mathrm{Fe}^{3+}$ ions. Concentration of $\mathrm{Mg}^{2+}$ ions after precipitation reaction with TSP is 7.27193 $\mathrm{ppm}$. Here, $\mathrm{Mg}^{2+}$ ions can also precipitate when added with phytic acid. To prevent the presence of $\mathrm{Fe}^{3+}$ ions in solution, $\mathrm{Mg}^{2+}$ ions must also be precipitated. Then the amount of PA was added must be slightly excessive. After addition with PA, the metal concentration in solution was measured using ICP-OES.

The concentration of impurities in PLS after reacted with PA has decreased compared to the concentration of impurities in PLS before adding PA. The concentration of $\mathrm{Al}$ as impurities in PLS with sulfuric acid concentration of $0.5 \mathrm{M}$ before PA was added at $563.662 \mathrm{ppm}$ and when added with PA, it decreased to $191.652 \mathrm{ppm}$ or $65.99 \%$. Concentration of $\mathrm{Mg}$ ion in PLS with $0.5 \mathrm{M}$ sulfuric acid is $7.27193 \mathrm{ppm}$ and after PLS was added with PA to be $3.49318 \mathrm{ppm}$ decreased by $51.96 \%$. Whereas, $\mathrm{Fe}$ ion content in PLS with $0.5 \mathrm{M}$ sulfuric acid was $24.6925 \mathrm{ppm}$ after the PLS was added with PA, the concentration of $4.57299 \mathrm{ppm}$, it is decreased by $81.48 \%$. However, the concentration of lanthanide ions increased.

Lanthanum and yttrium concentrations in PLS with a concentration of $0.5 \mathrm{M}$ sulfuric acid was $0.01513 \mathrm{ppm}$ and $0.15972 \mathrm{ppm}$, respectively, after the addition of PLS with $\mathrm{PA}$, their concentration were increased to $0.04411 \mathrm{ppm}$ $(34.03 \%)$ and $0.28431 \mathrm{ppm}(43.82 \%)$, respectively.

Decreasing of impurities on the PLS, the concentration of yttrium and lanthanum ions increased. Lanthanum and yttrium concentrations before TSP and PA were added to PLS with concentration of $0.5 \mathrm{M}$ of sulfuric acid solution of $0.00723 \mathrm{ppm}$ and $0.03069 \mathrm{ppm}$, and after added TSP and PA into PLS, lanthanum increased by $0.04411 \mathrm{ppm}$ which is $86.3 \%$, yttrium also increased to $0.28431 \mathrm{ppm}$, equivalent to $89.20 \%$ (see Table 6). These results showed that precipitation with TSP and PA could increase lanthanum and yttrium ions in the PLS. 
These results suggested that both lanthanum and yttrium can be extracted from Indonesian low grade bauxite using the series processes of heap acid leaching, precipitation and complexation methods.

Table 6. Comparison concentration of metals after precipitation reaction with PA ligand.

\begin{tabular}{|c|c|c|c|c|c|}
\hline$\frac{\ddot{e}}{a}$ & $\begin{array}{c}\mathrm{La} \\
(\mathrm{ppm})\end{array}$ & $\begin{array}{c}\mathrm{Y} \\
(\mathrm{ppm})\end{array}$ & $\begin{array}{c}\mathrm{Al} \\
(\mathrm{ppm})\end{array}$ & $\begin{array}{r}\mathrm{Mg} \\
(\mathrm{ppm})\end{array}$ & $\begin{array}{c}\mathrm{Fe} \\
(\mathrm{ppm})\end{array}$ \\
\hline$\cup$ & 0.04411 & 0.28431 & 191.652 & 3.49318 & 4.57299 \\
\hline
\end{tabular}

\section{Conclusion}

The lanthanides ( $\mathrm{La}$ and Y) have been successfully extracted from Indonesian low grade bauxite using heap leaching method with sulfuric acid, precipitated with trisodium phosphate and complexing with phytic acid (PA). The optimal concentration of $0.1 \mathrm{M}$ sulfuric acid $500 \mathrm{~mL}$, $20 \mathrm{~g}$ Indonesian low grade bauxite was dissolve $24.39 \%$ lanthanum and $34.03 \%$ yttrium. After the extraction process using $\mathrm{H}_{2} \mathrm{SO}_{4}$, then proceed with the precipitation process using trisodium phosphate. PA ligand has proven to precipitate some impurities such as $\mathrm{Al}, \mathrm{Fe}$ and $\mathrm{Mg}$ ions. Phytic acid successfully removed $57.125 \%$ of $\mathrm{Fe}^{3+}$ impurities in PLS. Separation the solid-liquid extraction using $\mathrm{H}_{2} \mathrm{SO}_{4}$, followed by precipitation using trisodium phosphate and phytic acid produce lanthanide with high purify. After sequencial two precipitations and complexations, the concentration of lanthanum and yttrium increased to $83.6 \%(0.04411 \mathrm{ppm})$ and $89.20 \%$ $(0.28431 \mathrm{ppm})$, respectively. This finding method is potential for the extraction of lanthanum and yttrium from Indonesian low grade bauxite with high efficiency.

\section{Acknowledgment}

The authors greatly acknowledge the Universitas Indonesia for research grant award through $\mathrm{HIBAH}$ SKEMA SUPERVISI BERSAMA Joint Supervisor grant), 2019. We also thank Dr. Ir. Muhamad Asvial, M.Eng. as vice of dean from Universitas Indonesia for his support on this proposal.

\section{References}

[1] S. Kumar, R. Kumar, A. Bandopadhyay, "Innovative methodologies for the utilisation of wastes from metallurgical and allied industries," Resour. Conserv. Recycl., vol. 48, no. 4, pp. 301-314, 2006.

[2] H. Sutar, S. C. Mishra, S. K. Sahoo, A. P. Chakraverty, and H. S. Maharana, "Progress of red mud utilization: An overview," American Chemical Science Journal, vol. 4, no. 3, pp. 255-279, 2014.

[3] G. Power, M. Gräfe, and C. Klauber," Bauxite residue issues: I. Current management, disposal and storage practices," Hydromet., vol. 108, no. 1, pp. 3345, 2011.

[4] K. Evans, "The history, challenges, and new developments in the management and use of bauxite residue," J. Sustain Metall., vol. 2, no. 4, pp. 316-331, 2016. doi:10.1007/s40831-016-0060-x.

[5] C. Klauber, M. Grafe, and G. Power, "Bauxite residue issues: II options for residue utilization," Hydrometallurgy, vol. 108, pp. 11-32, 2011.

[6] W. Wang, Y. Pranolo, and C. Y. Cheng, "Recovery of scandium from synthetic red mud leach solutions by solvent extraction with D2EHPA," Separation and Purification Technology, vol. 108, pp. 96-102, 2013.

[7] E. Kusrini, A. Usman, N. Trisko, S. Harjanto, and A. Rahman, "Leaching kinetics of lanthanide in sulfuric acid from low grade bauxite," Materials Today: Proceedings, vol. 18, pp. 462-467, 2019.

[8] E. Kusrini, Y. Nurani, and Z. J. Bahari, "Extraction of rare earth elements from low-grade Bauxite via precipitation reaction," in IOP Conf. Series: Materials Science and Engineering, 2018. doi:10.1088/1757899X/334/1/012052.

[9] E. Kusrini, Z. J. Bahari, A. Usman, A. Rahman, and E. A. Prasetyanto, "Recovery of Lanthanides from Indonesian low grade bauxite using oxalic acid," Materials Science Forum, vol. 929, no. 171-176, 2018.

[10] C. R. Borra, Y. Pontikes, K. Binnemans, and T. Van Gerven, "Leaching of rare earths from bauxite residue (red mud), Minerals Engineering, vol. 76, pp. 20-27, 2015.

[11] T. Thriveni, J. R. Kumar, C. Ramakrishna, Y. Jegal, and J. W. Ahn, "Rare earth elements gallium and yttrium recovery from (KC) Korean red mud samples by solvent extraction and heavy metals removal/stabilization by carbonation," in Rare Metal Technology. Springer, 2015, pp. 157-168.

[12] C. K. Gupta and N. Krishnamurthy, Extractive Metallurgy of Rare Earths. CRC Press, 2005.

[13] E. Alonso, A. M. Sherman, T. J. Wallington, M. P. Everson, F. R. Field, R. Roth, and R. E. Kirchain, "Evaluating rare earth element availability: A case with revolutionary demand from clean technologies," Environ. Sci. Technol., vol. 46, no. 6, pp. 3406-3414, 2012.

[14] G. Barrio and J. A. Osso, "Development of ${ }^{90} \mathrm{Sr}^{-}{ }^{90} \mathrm{Y}$ generators using the cation exchange technique at IPEN-CNEN-SP," Quarterly Journal of Nuclear Medicine and Molecular Imaging, vol. 54, no. 73, 2010.

[15] J. Vind, A. Mafliet, B. Blanpain, P. E. Tsakiridis, A. H. Tkaczyk, V. Vassiliadou, and D. Panias, "Rare earth element phases in bauxite residue," Minerals, vol. 8, p. 77, 2018. doi: 10.3390/min 8020077 .

[16] T. Thenepalli, R. Chikala, L. Habte, L. Q. Tuan, and C. S. Kim, "A brief note on the heap leaching technologies for the recovery of valuable metals," Sustainability, vol. 11, p. 3347, 2019. doi:10.3390/su11123347.

[17] J. Petersen, "Heap leaching as a key technology for recovery of values from low-grade ores-A brief 
overview," Hydrometallurgy, vol. 165, pp. 206-212, 2016.

[18] E. Kusrini, A. Zulys, A. Rachmana, D. A. Wulandari, Y. Muharam, A. Usman, and A. Rahman, "Enrichment and extraction of lanthanum from Belitung silica sand using sulfuric acid heap leaching, precipitation and complexation with phytic acid," Materials Today: Proceedings, to be published. [Online]. Available: https://doi.org/10.1016/j.matpr.2020.02.815

[19] M. Ochsenkiihn-Petropulu, T. H. Lyberopulu, K. M. Ochsenkiihn, and G. Parissakis, "Recovery of lanthanides and yttrium from red mud by selective leaching," Analytica Chimica Acta, vol. 319, pp. 249254, 1996.

[20] K. Nash, "Organophosphorus reagents in actinide separations: Unique tools for production, cleanup and disposal," Argonne National Laboratory, No. ANL/CHM/CP_100858, 2000. [Online]. Available: https://inis.iaea.org/collection/NCLCollectionStor e/_Public/31/047/31047202.pdf?r=1\&r=1

[21] H. Persson, M. Türk, M. Nyman, and A.-S. Sandberg, "Binding of $\mathrm{Cu}^{2+}, \mathrm{Zn}^{2+}$, and $\mathrm{Cd}^{2+}$ to inositol tri-, tetra-, penta-, and hexaphosphates," Journal of Agricultural and Food Chemistry, vol. 46, no. 8, pp. 3194-3200, 1998.

[22] P. Ekholm, L. Virkki, M. Ylinen, and L. Johansson, "The effect of phytic acid and some natural chelating agents on the solubility of mineral elements in oat bran," Food Chemistry, vol. 80, no. 2, pp. 165-170, 2003.

[23] E. Vasca, S. Materazzi, T. Caruso, O. Milano, C. Fontanella, and C. Manfredi, "Complex formation between phytic acid and divalent metal ions: A solution equilibria and solid state investigation," Analytical and Bioanalytical Chemistry, vol. 374, pp. 173 178, 2002. doi:10.1007/s00216-002-1469-6.

[24] C. Wu, Y. Cai, L. Xu, J. Xie, Zh. Liu, S. Yang, and S. Wang, "Macroscopic and spectral exploration on the removal performance of pristine and phytic aciddecorated titanate nanotubes towards Eu(III)," Journal of Molecular Liquids, vol. 258, pp. 66-73, 2018.

[25] X.-W. Cheng, J.-P. Guan, X.-H. Yang, R.-C. Tang, and F. Yao, "A bio-resourced phytic acid/chitosan polyelectrolyte complex for the flame retardant treatment of wool fabric," Journal of Cleaner Production, vol. 223, pp. 342-349, 2019.

[26] E. Kusrini, S. Harjanto, F. Herdino, E. A. Prasetyanto, and A. Rahman, "Effect of mechanochemical and roasting techniques for extraction of rare earth elements from Indonesian low-grade bauxite," IOP Conf. Series: Materials Science and Engineering, vol. 316, p. 012025, 2018.
[27] S. S. Abhilash, P. Meshram, and B. D. Pandey, "Metallurgical processes for the recovery and recycling of lanthanum from various resources-A review," Hydrometallurgy, vol. 160, no. 47-59, 2016.

[28] C.-J. Kim, H.-S. Yoon, K. W. Chung, J.-Y. Lee, S.-D. Kim, S. M. Shin, S.-J. Lee, A-R. Joe, S.-I. Lee, S.-J. Yoo, and S.-H. Kim, "Leaching kinetics of lanthanum in sulfuric acid from rare earth element (REE) slag," Hydrometallurgy, vol. 146, pp. 133-137, 2014.

[29] Z. Li, J. Din, J. Xu, C. Liao, F. Yin, T. Lu, L. Cheng, and J. Li, "Discovery of the REE minerals in the Wulong-Nanchuan bauxite deposits, Chongqing, China: Insights on conditions of formation and processes," J. Geochem. Explor., vol. 133, pp. 88-102, 2013.

[30] D. Beltrami, G. J. P. Deplonde, S. Belair, and V. Weigel, "Recovery of ytrium and lantanides from sulfate solutions with high concentration of iron and low rare earth content," Hydrometallurgy, vol. 157, pp. 356-362, 2015.

[31] J. Agin, N. Durupt, A. Greco, F. Hammy, G. Laroche, and J. Thiry, "Mise en solution et récupération d'au moins un élément $\mathrm{Nb}$, Ta et d'au moins un autre éléments $U$, terres rares à partir de minerais et concentrés," FR Patent 2970265A1, Jul. 13, 2012.

[32] L. Donati, B. Courtaud, and V. Weigel, "Maboumine process: A promising process for the developing a polymetallic ore deposit — focus on the upstream part of the process: rare earth recovery," in COM 2014_Conference of Metallurgists Proceedings, Victoria, Canada, June 22-25, 2014.

[33] E. P. Lokshin, O. A. Tareeva, K. G. Ivlev, and T. G. Kashulina, "A study of the solubility of double alkali metal $(\mathrm{Na}, \mathrm{K})$ rare earth (La, Ce) sulfates in sulfuricphosphoric acid solutions at $20{ }^{\circ} \mathrm{C}$.," Russ. J. Appl. Chem., vol. 78, no. 7, pp. 1080-1084, 2005.

[34] Z. He, C. W. Honeycutt, T. Zhang, and P. M. Bertsch, "Preparation and FT-IR characterization of metal phytate compounds, Journal of Environment Quality, vol. 35, no. 4, pp. 1319-28, 2006.

[35] E. M. Kök, M. Kogler, T. Bielz, B. Klötzer, and S. Penner, "In situ FT-IR spectroscopic study of $\mathrm{CO}_{2}$ and $\mathrm{CO}$ adsorption on $\mathrm{Y}_{2} \mathrm{O}_{3}, \mathrm{ZrO}_{2}$, and yttriastabilized $\mathrm{ZrO}_{2}$," The Journal of Physical Chemistry C, vol. 117, no. 34, pp. 17666-17673, 2013.

[36] U. Asghar, H. U. Rehman, S. A. U. Qader, and Z. T. Maqsood, "Influence of phytic acid and its metal complexes on the activity of pectin degrading polygalacturonase," Carbobydrate Polymers, vol. 95, no. 1, pp. 167-170, 2013. 

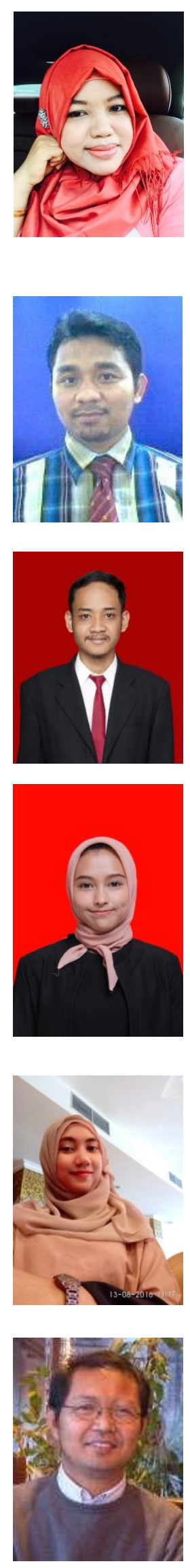

Anwar Usman was born in Medan, Indonesia in 1964. He received the B.S.c degree in Chemistry Department of Physics, Gadjah Mada University Yogyakarta, Indonesia in 1989, the M.S. degree in chemistry from Department of Chemistry, Graduate School, Tohoku University Sendai, Japan in 1997, and the Ph.D. degree in chemistry Department of Chemistry, Graduate School, Tohoku University Sendai, Japan in 2000. Since 2015, He has been as researcher and lecturer in the Department of Chemistry, Faculty of Science, Universiti Brunei Darussalam, Jalan Tungku Link, Gadong BE1410 Brunei Darussalam. His research interests include chemistry and nanotechnology. 